\title{
Self-reported altruism as predictor for active-empathic listening skills
}

\author{
Gabriela Mariana Marcu ${ }^{1^{*}}$ \\ ${ }^{1}$ Lucian Blaga University of Sibiu, Romania \\ *) Corresponding author, Ðe-mail: gabriela.marcu@ulbsibiu.ro
}

\begin{abstract}
While there are many consistent results regarding the altruism - empathy relationship, starting with the empathy-altruism hypothesis (Batson, 2008) and its confirmations or criticism, there is one specific aspect of empathy that has not often been associated with generosity: active listening. Our research hypothesizes that sharing one's attention in an empathic way (active-empathic listening) might be a skill linked to a person's generosity. A linear regression established that self-reported altruism (SRA) could statistically significantly predict someone's active-empathic listening skill (AELS), $\mathrm{F}(1,96)=28,965, \mathrm{p}=.0001$ and that SRA accounted for $22,4 \%$ of the explained variability in AELS. The results confirmed the initial claim and may have an impact in counseling practice, in career decision-making or in other studies on prosocial behavior.
\end{abstract}

Keywords: Altruism, active listening, empathy, prosocial behavior.

How to Cite: Marcu, G. (2020). Self-reported altruism as predictor for active-empathic listening skills. COUNS-EDU: The International Journal of Counseling and Education, 5(1), 23-28. DOI: http://doi.org/10.23916/0020200525810

This is an open access article distributed under the Creative Commons Attribution License, which permits unrestricted use,

distribution, and reproduction in any medium, provided the original work is properly cited. (C2020 by author.

\section{Introduction}

Active listening is defined by the International Listening Association (ILA; 2012) as "the process of receiving, constructing meaning from and responding to spoken and/or nonverbal messages". Active listening emerges from Rogers' conceptualization of empathic listening (Orlov, 1992), while activeemphatic listening is conceptualized as a type of listening important to relational and individual well-being (Bodie, 2011). Rogers formulated empathic listening as a psycho-therapeutic technique, manifested by unconditional acceptance and unbiased reflection of a client's experience. Researchers in interpersonal communication point out active-empathic listening (AEL) as the "active and emotional involvement of a listener that can take place in at least three key stages of the listening process" (Bodie, 2011; Drollinger, Comer, \& Warrington, 2006). AEL's sensing stage is measured concearning the sensitivity to the emotional needs of a speaker and manifests in the listener attending to both the implicit and explicit aspects of others' messages. The Processing stage of AEL refers to acts such as remembering, understanding, and comprehending conversational content and also integrating speaker's talk into a bigger picture. The Responding stage would be recognized by the use of verbal and nonverbal back-channeling and more extended responding, like question asking active attention. (Bodie, Gearhart, Denham, \& Vickery, 2013)

While demonstrating AELS validity within the interpersonal domain, Bodie concludes that "Now that a scale exists to measure AEL, the crucial task is to go about conducting research to discover what specific behaviors and traits are indicative of AEL." (Bodie, 2011). Not much research has been done in this direction, except an attempt to identify whether the Big-Five has predictive influences on communication competences of active-empathic listening (AEL) and assertiveness (Sims, 2017). Sims found out that Agreeableness and Openness highly predict AEL while a study run by Oda et. al linked 
agreeableness to altruism only toward friends/acquaintances, and openness to altruism only toward strangers (Oda et al., 2014). Even so, the results of the two studies raise hypotheses regarding a possible link between AEL and altruism.

As a specific prosocial behavior, altruism has raised many research questions and hypotheses that contributed to a puzzling picture of the concept. Moreover, specific associations with other constructs, like empathy started various debates on whether altruism could be taught, enforced or enhanced. Of course, practical and social implications are to be considered.

Juxtaposing altruism with egoism, Batson (Batson, 2008) defines it as a "motivational state with the ultimate goal of increasing another's welfare", distinguished from altruistic behavior, acting morally and helping to gain internal rather than external rewards. Other researchers are considering altruism as a driven behavioral response in social interaction, having empathy as a key motivator for altruistic behavior. In most psychological research, altruism is demonstrated through prosocial behaviors, which can be measured via self-report scales or through personality measures (Filkowski, Cochran, \& Haas, 2016)

However, the psychological factors that drive from and toward altruistic behavior have been poorly understood despite huge psychological research. Last decade research has established a close link between altruism and empathy, as the capacity to share the feelings of another. Klimecki, Mayer, Jusyte, Scheeff and Schönenberg (Klimecki, Mayer, Jusyte, Scheeff, \& Schönenberg, 2016) underlined some connections between meta-analytic evidence from psychology and the Adam Smiths's historical postulate on empathyaltruism link by showing how empathic states and traits might predict altruistic behavior. More recently, researchers in evolutionary psychology have suggested that in both humans and animals, empathy has evolved to promote altruism towards others in need, pain, or distress(de Waal, 2007). To provide more evidence for the healthcare professions, specifically in counseling, more studies were run on the empathyaltruism hypothesis, finding a significant association between the two (Burks, Youll, \& Durtschi, 2012; Huber \& MacDonald, 2012; Klimecki et al., 2016; Persson \& Kajonius, 2016). One aspect to consider here is the way the altruism is measured in the mentioned research. The cited studies used mostly economical games, like the Dictator Game (DG) scenarios to assess altruistic behavior (Behavioral paradigm). But one recent comparative study found no association between the self-reported altruism, measured with scale and so-called manifest altruism, measured with DG (Dana Bucuț ă \& Marcu, 2016).

We have chosen to use in this study the self-reported scale for measuring altruism, as it is compared to some other self-report construct, the active-empathic listening. As altruism is a concept about giving a personal resource to another or sharing it with another person, we may consider any of the situations involving such acts, like giving time, attention or ...both. This less investigated aspects of giving we consider as equally important as the material resources involved in generosity. In this particular case, we hypothesized that active listening, as an act of sharing attention is consistently associated with altruism, both measured on a self-rating scale. Moreover, we hypothesize that self-reported altruism (SRA) could statistically significantly predict someone's active-empathic listening skill.

\title{
Method
}

To test whether our active-empathic listening - altruism hypothesis confirms, we conducted a correlational study in which we compared the scores at AELS (Active-Empathic Listening Scale) with those from SRAS-DR (Self-Report Altruism Scale Distinguished by the Recipient).

The Active-Empathic Listening Scale (AELS) was originally developed by Drollinger et al (Drollinger et al., 2006) to assess effective versus ineffective listening for customers. Bodie (2011) adapted the 11-item scale to a more general social context, to measure active-empathic listening across three dimensions: sensing $(n=4)$, processing $(n=3)$, and responding $(n=4)$.

\author{
"Sensing refers to a listener's ability to understand the relational aspects of speech. \\ Processing, the cognitive aspect of listening, involves attending to, comprehending, \\ receiving, and interpreting messages. Responding measures the perception of the \\ behavioral output of listening including verbal and nonverbal feedback". (Bodie, 2011)
}

Self-reported altruism as predictor for active-empathic listening skills | 24 Indonesian Counselor Association (IKI) | DOI: https://doi.org/10.23916/0020200525810 
The scale can capture self-reported Active-empathic listening from a conversational partner, as well as ratings from trained coders. (Bodie, 2011). Self-Report Altruism Scale Distinguished by the Recipient is a 21-item scale, who evaluates altruism and the frequency of altruistic behaviors toward various recipients (family members, friends or acquaintances, strangers) in daily life (Oda et al., 2013). The scale has been adapted on the Romanian population in 2015 (Marcu \& Dana Bucuță, 2016). A total of 101 participants (mean age $=21.36$ years) completed the two scales, after the initial informed consent. Participants were first-year undergraduates in Psychology with little or no knowledge of experience in counseling. No other special conditions have been necessary for application.

\section{Results and Discussions}

The descriptive data showed an approximately normal distribution for each of the two variables (the data are little skewed and kurtotic, for both scales). As most statistical tests assume that data are normally distributed, we run an outlier identification before the data analysis. The Shapiro-Wink test for normality show a significant difference from normality for the SRAS-DR scale). We assumed that our data are approximately normally distributed, in terms of skewness and kurtosis.

Table 1 Normality tests for the two variables (active-empathic listening and altruism)

\begin{tabular}{|c|c|c|c|c|c|c|}
\hline \multicolumn{7}{|c|}{ Tests of Normality } \\
\hline & \multicolumn{3}{|c|}{ Kolmogorov-Smirnov $^{\mathrm{a}}$} & \multicolumn{3}{|c|}{ Shapiro-Wilk } \\
\hline & Statistic & $\mathrm{df}$ & Sig. & Statistic & $\mathrm{df}$ & Sig. \\
\hline AELS & ,066 & 98 &, $200^{*}$ & ,983 & 98 &, 241 \\
\hline SRAS & ,056 & 98 & ,200* & ,989 & 98 &, 594 \\
\hline \multicolumn{7}{|c|}{$\begin{array}{l}\text { a. Lilliefors Significance Correction } \\
* \text {. This is a lower bound of the true significance. }\end{array}$} \\
\hline
\end{tabular}
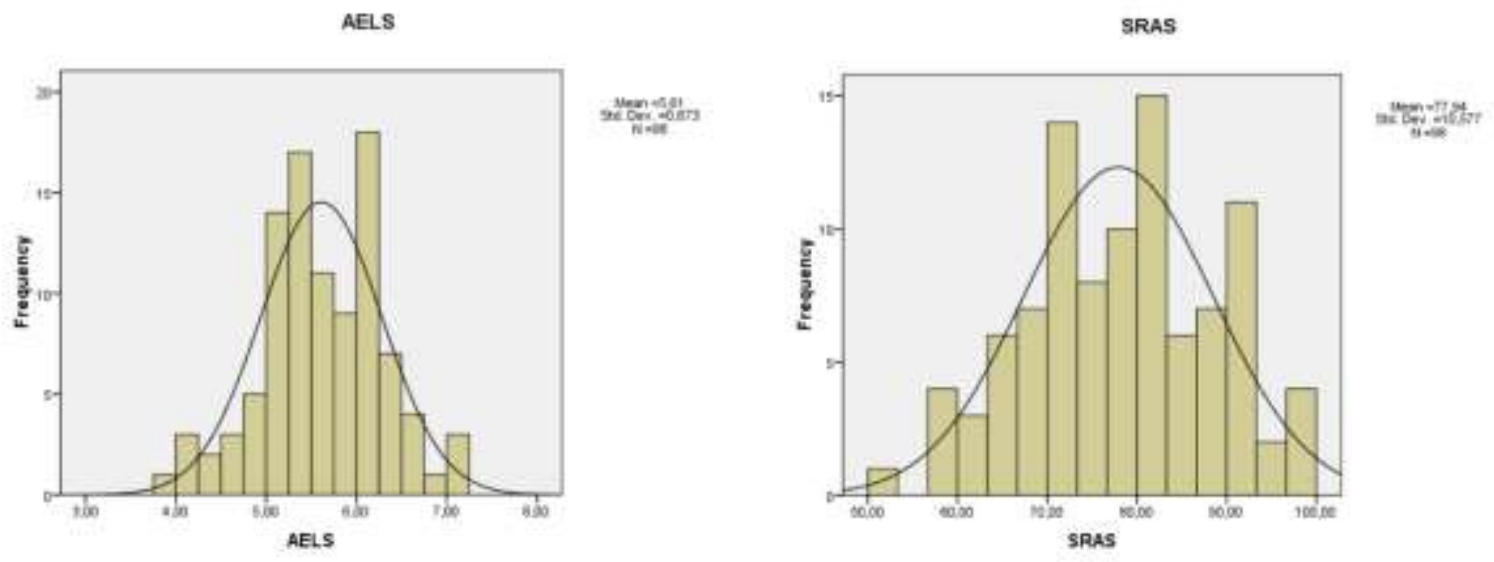

Figure 1. Frequency distribution of the two variables: AELS_TOT = Active- Empathic Listening Scale, SRAS_DR_TOT - Self-Reported Altruism Scale

A Pearson correlation test was runned, showing a significant association between the activeempathic listening and self-reported altruism: $r(98)=+.481, \mathrm{p}<.01$, two-tailed. 
Table 2. Correlation between active-empathic listening and altruism

\begin{tabular}{llll}
\hline & & Correlations & SRAS \\
AELS & Pearson Correlation & AELS &, $481^{* *}$ \\
& Sig. (2-tailed) & 1,000 &, 000 \\
\multirow{4}{*}{ SRAS } & N & & 98 \\
& Pearson Correlation & 98,000 & 1,000 \\
& Sig. (2-tailed) &, $481^{* *}$ & 98,000 \\
& N &, 000 & 98 \\
\end{tabular}

Notes: AELS = Active-Empathic Listening Scale, SRAS - Self-Reported Altruism Scale.

$* * \mathrm{p}<0.01(2-$ tailed $)$

\section{Regression Analysis}

Regression analysis was run to determine if self-reported altruism predicted active-empathic listening. The regression analysis revealed that self-reported generosity significantly predicted active-empathic listening (or attention-sharing with another person), explaining $22,4 \%$ of the variance ( $R 2=0.32$, adj $\mathrm{R} 2=0,224$, $\mathrm{F}(1,97)=28,97, \mathrm{p}<0.001)$.

The two variables were also tested for independence. The Durbin-Watson test value $(1,711)$ is between 1.5 and 2.5 and therefore the data is not autocorrelated.

Table 3 Regression analysis

\begin{tabular}{|c|c|c|c|c|c|}
\hline \multicolumn{6}{|c|}{ Model Summary } \\
\hline Model & $\mathrm{R}$ & R Square & Adjusted R Square & $\begin{array}{l}\text { Std. Error of the } \\
\text { Estimate }\end{array}$ & Durbin-Watson \\
\hline 1 &, $481^{\mathrm{a}}$ & 232 & 224 & 9,31867 & 1,711 \\
\hline \multicolumn{6}{|c|}{$\begin{array}{l}\text { a. Predictors: (Constant), AELS } \\
\text { b. Dependent Variable: SRAS }\end{array}$} \\
\hline
\end{tabular}

\begin{tabular}{|c|c|c|c|c|c|c|}
\hline \multicolumn{7}{|c|}{ ANOVA $^{b}$} \\
\hline Model & & Sum of Squares & $\mathrm{df}$ & Mean Square & & Sig. \\
\hline \multirow[t]{3}{*}{1} & Regression & 2515,219 & 1 & 2515,219 & 28,965 &, $000^{\mathrm{a}}$ \\
\hline & Residual & 8336,413 & 96 & 86,838 & & \\
\hline & Total & 10851,633 & 97 & & & \\
\hline \multicolumn{7}{|c|}{ a. Predictors: (Constant), AELS } \\
\hline \multicolumn{7}{|c|}{ b. Dependent Variable: SRAS } \\
\hline
\end{tabular}

\begin{tabular}{|c|c|c|c|c|c|c|c|c|c|c|}
\hline \multicolumn{11}{|c|}{ Coefficients $^{\mathrm{a}}$} \\
\hline Model & \multicolumn{2}{|c|}{$\begin{array}{l}\text { Unstandardized } \\
\text { Coefficients }\end{array}$} & \multirow{2}{*}{$\begin{array}{l}\text { Standardized } \\
\text { Coefficients } \\
\text { Beta }\end{array}$} & $\mathrm{t}$ & \multirow[t]{2}{*}{ Sig. } & \multicolumn{3}{|c|}{ Correlations } & \multicolumn{2}{|c|}{$\begin{array}{l}\text { Collinearity } \\
\text { Statistics }\end{array}$} \\
\hline & B & $\begin{array}{l}\text { Std. } \\
\text { Error }\end{array}$ & & & & $\begin{array}{l}\text { Zero- } \\
\text { order }\end{array}$ & Partial & Part & Tolerance & VIF \\
\hline 1 (Constant) & 35,461 & 7,949 & & 4,461 & ,000 & & & & & \\
\hline AELS & 7,570 & 1,407 & ,481 & 5,382 &, 000 & ,481 & ,481 & ,481 & 1,000 & 1,000 \\
\hline
\end{tabular}




\begin{tabular}{|c|c|c|c|c|c|}
\hline \multicolumn{6}{|c|}{ Collinearity Diagnostics $^{\mathrm{a}}$} \\
\hline \multirow[t]{2}{*}{ Model } & \multirow[t]{2}{*}{ Dimen-sion } & \multirow[t]{2}{*}{ Eigenvalue } & \multirow[t]{2}{*}{ Condition Index } & \multicolumn{2}{|c|}{ Variance Proportions } \\
\hline & & & & (Constant) & AELS \\
\hline \multirow[t]{2}{*}{1} & 1 & 1,993 & 1,000 &, 00 & ,00 \\
\hline & 2 &, 007 & 16,829 & 1,00 & 1,00 \\
\hline
\end{tabular}

Notes: AELS = Active- Empathic Listening Scale, SRAS - Self-Reported Altruism Scale.

AELS

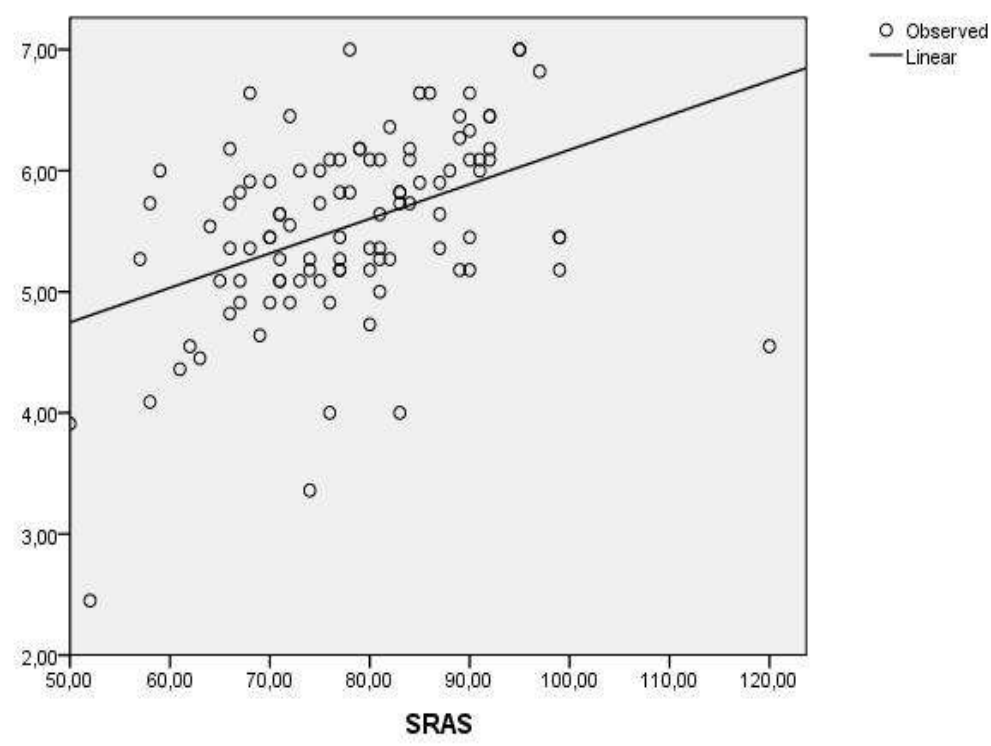

Figure 2. Mean increase of self-reported altruistic behavior (SRAS) predicted mean increase of activeempathic listening (AELS), $\mathrm{n}=98$.

\section{Conclusions}

Like some big-five traits were identified as predictors for AEL (Sims, 2017), we pointed out selfreported altruism as another possible predictor for this interpersonal skill. Conceptualization of AEL received the dimension of attention-sharing in the present study, as in interpersonal relationships, sharing is considered a prosocial behaviour defined by the joint use of resources or space. Attention-sharing was considered non-material resource, but also finite and costly for the giver and it was measured by the activeempathic listening scale, providing insightful results in the relationship with the self-reported altruism. The data confirm the altruism-active listening link hypothesis, which can expand the prosocial behavior description, in human interactions. The study's findings show that altruism, measured by a self-reporting scale, is a predictor for active listening (or attention-sharing). Data is complementary to previous work results, which observed powerful associations between empathy and altruistic behaviour in economic games (Klimecki et al., 2016), altruistic behaviour and big five traits (Oda et al., 2014) or personality traits and AEL (Sims, 2017). Therefore, our findings extend previous evidence on the relationship between empathy and altruism showing that the amount of self-reported altruism strongly predicts how strong the active-empathic listening skills one can have. 


\section{Acknowledgments}

Study was partially financed from Lucian Blaga University research grants LBUS-IRG-2016-02.

\section{References}

Batson, C. D. (2008). Empathy-Induced Altruistic Motivation. Herzliya Symposium on Prosocial Motives, Emotions, and Behavior, 1-32. https://doi.org/http://dx.doi.org/10.1037/12061-001

Bodie, G. D. (2011). The active-empathic listening scale (AELS): Conceptualization and evidence of validity within the interpersonal domain. Communication Quarterly, 59(3), 277-295. https://doi.org/10.1080/01463373.2011.583495

Bodie, G. D., Gearhart, C. C., Denham, J. P., \& Vickery, A. J. (2013). The Temporal Stability and Situational Contingency of Active-Empathic Listening. Western Journal of Communication, 77(2), 113-138. https://doi.org/10.1080/10570314.2012.656216

Burks, D. J., Youll, L. K., \& Durtschi, J. P. (2012). The Empathy-Altruism Association and Its Relevance to Health Care Professions. Social Behavior and Personality: An International Journal, 40(3), 395-400. https://doi.org/10.2224/sbp.2012.40.3.395

Bucuț ă, M.D., \& Marcu, G. (2016). Altruism From Intention To Action: A Psychological Comparison Of Self-Reported Vs. Manifest Altruism. In Working Papers Volume LUMEN RSACV 2015. Retrieved from https://www.researchgate.net/publication/279913911

de Waal, F. B. M. (2007). Putting the Altruism Back into Altruism: The Evolution of Empathy. Annual Review of Psychology, 59(1), 279-300. https://doi.org/10.1146/annurev.psych.59.103006.093625

Drollinger, T., Comer, L. B., \& Warrington, P. T. (2006). Development and validation of the active empathetic listening scale. Psychology and Marketing, 23(2), 161-180. https://doi.org/10.1002/mar.20105

Filkowski, M., Cochran, R. N., \& Haas, B. (2016). Altruistic behavior: mapping responses in the brain. Neuroscience and Neuroeconomics, Volume 5, 65-75. https://doi.org/10.2147/nan.s87718

Huber, J. T., \& MacDonald, D. A. (2012). An investigation of the relations between altruism, empathy, and spirituality. Journal of Humanistic Psychology, 52(2), 206-221. https://doi.org/10.1177/0022167811399442

ILA, (2012), Definition of listening. International Listening Association. Retrieved from http://www.listen.org

Klimecki, O. M., Mayer, S. V., Jusyte, A., Scheeff, J., \& Schönenberg, M. (2016). Empathy promotes altruistic behavior in economic interactions. Scientific Reports, 6. https://doi.org/10.1038/srep31961

Marcu, G., \& Bucuț ă , M.D. (2016). Adaptation and validation of Japanese Self-Report Altruism Scale Distinguished by the Recipient (SRAS-DR) on Romanian population. In Working Papers Volume LUMEN RSACV 2015. Retrieved from https://www.researchgate.net/publication/ 279914119

Oda, R., Dai, M., Niwa, Y., Ihobe, H., Kiyonari, T., Takeda, M., \& Hiraishi, K. (2013). Self-Report Altruism Scale Distinguished by the Recipient (SRAS-DR): Validity and reliability. Shinrigaku Kenkyu, 84(1), 28-36. https://doi.org/10.4992/jjpsy.84.28

Oda, R., Machii, W., Takagi, S., Kato, Y., Takeda, M., Kiyonari, T., ... Hiraishi, K. (2014). Personality and altruism in daily life. Personality and Individual Differences, 56, 206-209. https://doi.org/10.1016/j.paid.2013.09.017

Orlov, A. B. (1992). Carl Rogers and Contemporary Humanism. Journal of Russian \& East European Psychology, 30(1), 36-41. https://doi.org/10.2753/rpo1061-0405300136

Persson, B. N., \& Kajonius, P. J. (2016). Empathy and universal values explicated by the empathyaltruism hypothesis. Journal of Social Psychology, 156(6), 610-619. https://doi.org/10.1080/00224545.2016.1152212

Sims, C. M. (2017). Do the Big-Five Personality Traits Predict Empathic Listening and Assertive Communication? International Journal of Listening, 31(3), 163-188. https://doi.org/10.1080/10904018.2016.1202770 